\title{
A INTELIGÊNCIA HUMANA: CONTORNOS DA PESQUISA ${ }^{1}$
}

\author{
Maria José Miranda ${ }^{2}$ \\ FPCE - Universidade de Lisboa
}

\begin{abstract}
RESUMO: A inteligência humana é entendida e abordada como um conceito plural, que marca o comportamento adaptativo. $\mathrm{O}$ artigo toca as definições conceituais e operacionais, a distinção entre concepções implícitas e explícitas, e as teorias explícitas categorizadas em paradigmas em que confluem as metáforas subjacentes da pesquisa psicológica no domínio da inteligência, e examina dois modelos sistêmicos da organização adaptativa. O desenvolvimento das tecnologias da observação e da análise das evidências acentuarão seguramente a interdisciplinaridade da pesquisa, cientificamente rica e socialmente promissora, porque integrativa.
\end{abstract}

Palavras-chave: inteligência; adaptação; paradigmas da investigação; auto-organização; interdisciplinaridade

\section{ON CONTOURS OF RESEARCH IN HUMAN INTELLIGENCE}

ABSTRACT: Human intelligence is understood and referred to as a plural concept, which shapes adaptative behavior. The paper considers conceptual and operational definitions of intelligence, implicit and explicit theories, major paradigms of research and underlying metaphors on mental processing, and examines two systemic models of self-management. The variety of techniques of data collection and experimental evidence analysis will definitely enhance the interdisciplinary framework of the research on human intelligence, scientifically sound and socially pervasive, for its integrative nature.

Key-words: intelligence; adaptation; research paradigms; self-management; interdisciplinarity.

$\mathrm{Na}$ linguagem comum, a palavra inteligência refere uma qualidade dos indivíduos. Na linguagem científica, refere uma qualidade do comportamento.

As raízes do estudo científico da inteligência humana podem ser datadas pelo interesse pelas manifestações extremas dessa qualidade do comportamento: a genialidade e a deficiência funcional. Os desenvolvimentos são ditados pelo interesse pelos mecanismos da adaptação.

A literatura psicologica sobre a inteligência humana, para além de vastíssima nos vários domínios da própria Psicologia, é extremamente diversificada: quanto aos pontos de partida, aos objetivos, às metodologias, ao enquadramento.

\footnotetext{
${ }^{1}$ Artigo recebido para publicação em janeiro de 2002; aceito em junho de 2002

2 Endereço para correspondência: Maria José Miranda, Faculdade de Psicologia e Ciências da Educação, Universidade de Lisboa, Alameda da Universidade, Cep. 1649-013, Lisboa, Portugal E-mail mimiranda@reitoria.ul.pt
}

Entende-se aqui por contornos a envolvente epistemológica, a montante das teorias e dos modelos, da própria pesquisa.

\section{Da Problemática}

Num texto recente, Nathan Brody refere-se aos artigos de Spearman de 1904 ('General intelligence' objectively determined and measured) e de Binet \& Simon de 1905 (Méthodes nouvelles pour le diagnostic du niveau intellectuel des anormaux) como os trabalhos que marcaram definitivamente a investigação da inteligência humana ao longo de todo o século XX (Brody, 2000): o primeiro, no sentido da modelização pioneira do construto inteligência; o segundo, no sentido da operacionalização pioneira do construto inteligência. Mesmo se o argumento é relativamente simplista, equaciona de fato grandes parâmetros da investigação científica: os de nível de 


\section{Maria José Miranda}

observação e de nível de análise. Aborda a investigação científica (no sentido do caráter público dos métodos utilizados e da replicabilidade dos resultados encontrados), no que se refere à descrição e à explicação, e muito designadamente numa ciência da vida como é o caso da Psicologia, que se ocupa do ser vivo (o humano, em particular) em condições habituais de vida (Reuchlin, 1999).

O construto inteligência: construto enquanto construção teórica e/ou empírica em que se alicerça a investigação, isto é, construção por natureza hipotético-dedutiva, logo simultaneamente heurística e hermenêutica. Seguramente isto condiz às exigências de pertinência científica e relevância social. Mas será igualmente significativo e útil para o indivíduo e para a sociedade?

Retomando os referenciais de Brody (2000), no termo de praticamente um século de investigação fundamental e aplicada, situar-nos-emos nós muito longe da resposta atribuída a Alfred Binet, proferida pouco depois da publicação da sua Escala Métrica, à pergunta "o que é a inteligência?". Em resposta: "a inteligência é o que a minha Escala mede" (A literatura americana de língua inglesa refere preferencialmente a mesma, afinal definição operacional, do conceito, atribuindo-a a Edwin Boring e formalizada no seu artigo de 1923, Intelligence as the tests test it). Teremos explorado consistentemente alguns pontos básicos, tais como a univocidade versus polimorfismo do conceito, a articulação elementarismo versus estruturalismo, o jogo das influências cognitivas versus afetivo-emocionais e a interculturalidade versus relativismo do comportamento 'inteligente'? Teremos refletido consistentemente sobre a questão posta por David Wechsler, no seu discurso quando da atribuição do Distinguished Professional Contribution Award pela Associação Americana de Psicologia em 1974, em termos de "o que é medido pelos testes não é o que os testes medem (...). O que os testes [de inteligência] medem é algo muito mais importante: a capacidade de um indivíduo para compreender o mundo à sua volta e o conjunto dos seus recursos para enfrentar os desafios que ele the coloca" (Wechsler, 1975, p. 139)? Ou ter-nos-emos efetivamente quedado ao nível do comentário de John Stuart Mill sobre o conceito de bem-estar, "toda a gente tem uma noção suficientemente correta - no que toca os efeitos práticos"?

\section{Do Conceito e do Construto}

Dois Simpósios, o primeiro organizado pelos editores do Journal of Educational Psychology em 1921 (Thorndike, 1921) e o segundo em meados da década de 80 (Sternberg \& Detterman, 1986), continuam a constituir referências de grande interesse relativas ao conceito / construto de inteligência (Miranda, 1986; Miranda, 2000, prelo).

No aspecto da sua natureza, o coeficiente de correlação da ordem de .50 entre as freqüências de ocorrências listadas (comportamentos como raciocínio abstrato, processamento da informação, adaptação ao meio) põem em evidência alguma sobreposição entre as concepções explícitas dos especialistas, distanciadas várias gerações. Por outro lado, há emergência, com o tempo, de duas novas preocupações (Sternberg, 2000): os aspectos metacognitivos e os aspectos situacionais do comportamento inteligente.

Há mais de 20 anos a questão do "protótipo" relativamente ao qual se situaria a singularidade (a idiossincrasia individual) foi levantada por $U$. Neisser. Constituindo um protótipo uma instância comportando todas as propriedades típicas de algo, o procedimento científico mais heurístico fundamenta-se na recolha de uma multiplicidade de evidência empírica, e sua articulação. Recolha de evidência tão ampla quanto possível, e construção de modelos compreensivos e extensivos, ainda que não necessariamente exaustivos (Neisser, 1979). Por outras palavras, a prevalência, no estudo da inteligência humana, da operacionalização do construto sobre a definição do conceito.

A noção de protótipo é lida por Robert Sternberg como o prelúdio do último ato de uma peça de teatro a estrear no ano 2000 , com o título 'Seis autores em busca de uma personagem', de cuja estréia se assume como o crítico teatral. À imagem, na inversa, da do Nobel da Literatura de 1934, Luigi Pirandello, a temática da peça é centrada numa assembléia de autores que procuram o dirigente legítimo do 'País da Inteligência'. Os dirigentes anteriores e a sua atuação, infirmaram de reconhecimento consensual durável. Designadamente o Senhor $\mathrm{Fa}$ - 


\section{A Inteligência Humana}

tor, nas várias organizações assumidas (a monárquica, a oligárquica, a hierárquica, a anárquica, que nem as tentativas de alternância por rotatividade foram capazes de salvar), que viria a ser derrubado pelo Senhor Metacomponente, responsável de uma ordem nova, caracterizada esta pela primazia da organização do poder sobre a estrutura do próprio poder; nova ordem, no entanto, fragilizada pelo importante papel de quadros superiores, como o Senhor Aprendizagem, o Senhor Transferência, o Senhor Memória. A dinâmica da peça gera ainda questões aparentemente não centrais, como as atividades dirigidas em contraposição com as do dia a dia, a valorização cultural de certas atividades em detrimento de outras, $\mathrm{e}$ as implicações educativas (Sternberg, 1979). Omite-se aqui, e intencionalmente, o último ato da peça, naturalmente datado, e caído na armadilha, aliás prevista pelo crítico teatral, nas suas palavras o risco " de [vir a] ser ridiculizado por autores de uma peça sobre os testes de inteligência no ano 3000 ou mesmo 2100" (p. 258).

A alegoria reporta-se claramente às abordagens diferencialista e cognitivista em psicologia da inteligência humana, e às perspectivas globalista e elementarista da investigação. A personagem emergente é, naturalmente, a mais cara ao autor nessa época: a análise componencial da inteligência (Sternberg, 1977). São claramente aludidos os grandes modelos fatoriais e a 'revolução' cognitivista, suas mais valias e fragilidades, e até as eventuais (e acontecidas) resolução de antinomias e convergência metodológica. Como são aludidos o relativismo cultural e os contextos situacionais. E estão subjacentes, pelo menos à distância de 20 anos, as conotações hoje designadas de teorias implícitas e explícitas da inteligência humana.

\section{Das Teorias Implícitas da Inteligência Humana}

A designação refere-se a concepções geradoras de apreciações e juízos globais sobre as pesssoas, e que influenciam práticas e decisões. As teorias explícitas formuladas pelos especialistas são construções baseadas ou testadas em dados da observação do funcionamento intelectual em situações estandardizadas, na evidência empírica, portanto. As implícitas, são construções informais, sistemas de crenças mais ou menos formalizadas e cuja natureza, conteúdo e aspectos são suscetíveis de fornecer informação relevante ao trabalho científico.

Para Sternberg, o seu estudo importa no que se refere a monitorização das elaborações do próprio investigador, ao confronto com construtos da sua e de outras teorias explícitas, à compreensão do comportamento motivado, à compreensão de mudanças desenvolvimentistas ao longo da vida, e à diversidade cultural (Sternberg, 1990). Sternberg e colaboradores desenvolveram vários estudos com adultos e com crianças visando à identificação de categorias de comportamentos "inteligentes" em grupos transversais diferenciados, sua comparação e comparação com dimensões bem estipuladas da teoria psicológica (Sternberg, 2000).

Um desses estudos (Sternberg, Conway, Ketron \& Bernstein, 1981) incidiu sobre os conceitos implícitos de inteligência, de inteligência "acadêmica", e de inteligência do dia a dia. Os participantes foram de amostras de ocasião, estudantes universitários e psicólogos doutorados de universidades e centros de investigação, e pessoas comuns em situações do quotidiano. Três planos experimentais, metodologicamente distintos, foram organizados; as tarefas incluíam listagem de comportamentos, auto-avaliação, aplicação de uma técnica diferencial para fins comparativos com resultados de auto-avaliação, avaliação de indivíduos fictícios.

Dois grandes aspectos emergentes da inventariação, pelos sujeitos das experiências, de "comportamentos inteligentes" podem ser realçados do estudo. O primeiro, assimilações consistentes, por parte dos universitários, do conceito de inteligência a inteligência acadêmica, e do mesmo à inteligência do dia a dia por parte do outro grupo, genericamente os "leigos". Por outras palavras, uma valorização diferencial das qualidades ligadas a prossecução de estudos e das ligadas à vida na comunidade. O segundo, os padrões dominantes dos dois grupos (universitários e leigos) postos em evidência pela análise fatorial: no grupo leigo, três fatores, fator 1 aptidão para resolver problemas práticos, fator 2 aptidão verbal, fator 3 competência social, explicam $46 \%$ da variância dos resultados; no grupo não leigo, de novo três fatores explicam $51 \%$ da variância, inteligência verbal, resolução de problemas e inteli- 


\section{Maria José Miranda}

gência prática. No grupo leigo; o fator 1 (aptidão para resolver problemas práticos) explica dois terços da variância total; no grupo não leigo, os fatores inteligência verbal e resolução de problemas, mais de $80 \%$. Por outras palavras, um entendimento diferencial de facetas críticas da inteligência, ao serviço da adaptação.

\section{Dos Paradigmas e Metáforas}

As teorias explícitas da inteligência humana enquadram-se em quatro grandes paradigmas, os quais cobrem praticamente os grandes modelos e técnicas até meados dos anos 80: são eles o biológico, o diferencial, o construtivista e o informacional (Miranda, 1986, 2000, prelo).

O paradigma biológico tem as suas raízes no século de ouro da Grécia Antiga: Hipócrates (460377 , a.c.), por exemplo, referiu-se à cabeça, ao cérebro, como sede do pensamento. Já no século das luzes, a teoria frenológica de Franz Joseph Gall (17581828) teve mais impacto na crença popular do que na ciềncia, mesmo a do seu tempo que a rejeitou: a configuração do crânio reproduziria a estrutura do cérebro onde se localizariam as diferentes funções cognitivas; as protuberâncias cranianas constituiriam, assim, indicadores do desenvolvimento de "faculdades mentais".

A teoria neuropsicológica de D. Hebb distingue a Inteligência A e a Inteligência B: a primeira, significa o potencial inato, isto é, a capacidade do sistema nervoso central que inclui a do seu próprio desenvolvimento, não observável nem mensurável; a segunda, observável e mensurável, é o resultado da interação da Inteligência A com o meio, isto é, o fenótipo (Hebb, 1949). Na teoria de Cattell (1987), a inteligência fluida ( $\mathrm{gf}$ ) é biologicamente organiza$\mathrm{da}$, constitucional portanto, e significa o funcionamento intelectual biologicamente determinado.

Os estudos da atividade cerebral têm examinado a relação entre a estrutura e o funcionamento do cérebro e o processamento da informação: velocidade da condução neuronal, potenciais evocados, metabolismo da glucose, especialização hemisférica. Algumas consistências com o desempenho em testes de inteligência têm sido apontadas (Eysenck, 1982), e a via é por muitos autores considerada pro- missora para a investigação e para a prática clínica (Matarazzo, 1992; Vernon et al., 2000).

$\mathrm{Na}$ área da neurobiologia, os trabalhos do cientista português Antônio Damásio na Universidade de Iowa constituem uma referência incontornável do final do último milênio. O conceito básico da obra mundialmente famosa (Damásio, 1994) é relativamente simples: na terminologia cartesiana, não há res cogitans sem res extensa = não há cogito sem corpo $=$ não há pensamento sem o substrato neurobiológico.

O paradigma diferencial radica na evidência das diferenças individuais. Os construtos psicológicos subsumem as diferenças observadas em dimensões. No limite, as dimensões descrevem todos os indivíduos e, por conseqüência, explicam a idiossincrasia. A teoria, a lei, passa pelas diferenças.

O paradigma diferencial é eminentemente avaliativo: a avaliação é o ponto de partida (averiguação da variabilidade do desempenho), a avaliação é o ponto de chegada (indicadores de competência (s) e partilha da informação favorecedora do autoconhecimento). Os dois grandes motores dos desenvolvimentos teóricos e práticos foram e são a evolução dos métodos de observação e a evolução dos métodos de análise de dados. Destes, a análise fatorial (redução da multiplicidade das observações a um pequeno número de fatores explicativos) ocupa um lugar proeminente na teoria psicológica (modelos e técnicas), como na teoria dos testes (validação das medidas). Mais recentemente, os modelos estruturais abrem novas vias à exploração dos dados e, conseqüentemente, a modelização.

O paradigma construtivista é indissociável de J. Piaget, "zoólogo por formação, epistemólogo por vocação, e logicista por método" (Miranda, 1986, p. 36). Inteligência é adaptação: no plano mental se prolonga e conclui o conjunto de processos adaptativos, cujo ponto de partida são as trocas entre o organismo e o meio que caracterizam a adaptação biológica. Adaptação é assimilação (o sujeito age sobre o meio, no sentido de apreensão e incorporação das instâncias do meio) e acomodação (o meio age sobre o sujeito, no sentido de modificação das estruturas existentes). Assimilação e acomodação são comuns ao orgânico, a ação, e ao pensamen- 
to - invariantes, portanto, da vida, e a lei funcional da inteligência. $O$ desenvolvimento humano é uma sucessão de grandes construções. No construtivismo psicogenético, o desenvolvimento é uma marcha para o equilíbrio, e cada construção integra e reorganiza, num plano superior, as que a antecedem.

O paradigma informacional centra-se nos mecanismos da cognição, isto é, os "programas" do processamento da informação. No estudo das representações e dos processos entram os correlatos, os componentes e os conteúdos cognitivos e o treino cognitivo, nos aspectos da consistência, da variabilidade e da mudança. A teoria componencial da inteligência humana (Sternberg, 1977) articula, com base no raciocínio analógico, os processos e as estratégias com as aptidões.

A metodologia da avaliação privilegia as tarefas e processamento dos estímulos, em laboratório, e recorrendo a tecnologia altamente sofisticada. Os modelos decorrentes são, freqüentemente, ou demasiado circunscrito ou demasiado gerais, e não têm em conta a variabilidade, individual como situacional. $\mathrm{O}$ paradigma informacional introduz definitivamente, na investigação em psicologia da inteligência humana, por um lado a acentuação dos processos básicos da representação/ retenção/ processamento da informação e, por outro, a importância de processos mais gerais, de natureza integradora (genericamente, a metacognição).

Os paradigmas (Kuhn, 1983) supõem metáforas, para cujas questões a investigação científica procura as respostas. Na psicologia da inteligência humana R. Sternberg encontra sete metáforas, que descreve em termos de duas categorias de "perguntas motivantes", a inicial e a derivada. A pergunta inicial, ou "pressuposta" como a refere o autor, centra-se na relação entre inteligência e os mundos interior e exterior das pessoas; a derivada, na forma primitiva de resposta (Sternberg, 1990, 2000). Noutros termos, as teorias implícitas e as hipóteses condutoras da investigação.

As metáforas geográfica, informacional, biológica e epistemológica (ou genético-epistemológica) tratam a pergunta pressuposta qual a relação entre a inteligência e o mundo interno do indivíduo?'; as metáforas antropológica e sociológica, 'que relação entre a inteligência e o mundo externo do individuo?'.
A metáfora sistêmica poderá ser entendida como um empreendimento transversal, a relação da inteligência com os mundos externo e interno do indivíduo.

Caracteriza a metáfora geográfica o mapa mental emergente das diferenças individuais, designadamente os modelos fatoriais. A unidade base é o fator. Exemplos relevantes, as teorizações de Spearman, Thurstone, Guilford, Cattell, Vernon, Carroll. Sternberg aponta como pontos fortes a especificação de estruturas que descrevem (e explicam) o funcionamento cognitivo, a operacionalização dos construtos, a tecnologia disponível de recolha e de tratamento de dados. Como pontos fracos, a insuficiente consideração dos processos intervenientes, a dependência estrita das diferenças individuais, os riscos da análise fatorial exploratória, incluindo o da alguma indeterminação na escolha das modalidades de rotação dos eixos, e a limitada generalização para as atividades do dia a dia.

A metáfora informacional centra-se nas rotinas do processamento da informação que o pensamento utiliza. A unidade base é o componente. Os estudos cognitivistas de Hunt e os seus próprios sobre o raciocínio analógico (Sternberg, 1977) enquadram-se aqui. As vantagens, a especificação dos processos e estratégias mentais, a análise do desempenho em tempo real, a simulação por computador. As limitações, a insuficiente consideração das estruturas mentais enquanto fontes de diferenças individuais, a questionável analogia computacional e, uma vez mais, a limitada generalização para as atividades do dia a dia.

A metáfora biológica funda-se na anatomia e físiologia do cérebro e do sistema nervoso central da ótica da ligação com o desempenho de tarefas cognitivas. A unidade base varia conforme as pistas de pesquisa - potenciais evocados, velocidade e eficácia da transmissão neuronal, especificidade funcional - e, mais recentemente, em função dos dados fornecidos pelas novas tecnologias tomográficas e de scanning. Os pontos fortes são as associações mais ou menos consistentes das atividades cognitiva e neurobiológica, o rigor das técnicas experimentais, e a eventual abertura a avaliação relativamente independente da aculturação. As limitações, a pelo menos ainda reduzida aplicabilidade prática, a negligência dos contextos em que se reali- 
za o comportamento inteligente, e atribuição causal insuficientemente suportada pela evidência experimental.

A metáfora genético-epistemológica gera a procura às estruturas em que se organizam o conhecimento e os processos mentais. A unidade base é o 'esquema'. A metodologia da observação privilegia a experimentação em estudo de casos. $O$ construtivismo psicogenético oferece uma teoria compreensiva da inteligência e do desenvolvimento cognitivo e integra a descrição de estruturas e processos a partir de uma enorme extensão e variedade de dados obtidos da infância à adolescência. Para Sternberg (2000), as limitações intrínsecas decorrem da ênfase numa margem etária relativamente estreita e da concentração na lógica do pensamento em detrimento de outros aspectos do comportamento inteligente.

Como referido antes, nas metáforas antropológica e sociológica o acento é deslocado para o mundo externo ao indivíduo. A metáfora antropológica é bem ilustrada nos estudos interculturais (o que de modo nenhum significa negligência da interculturalidade ou transculturalidade noutras abordagens). A questão central é o contorno cultural da inteligência, que emerge da organização manifesta do pensamento inteligente (tarefas de categorização, por exemplo). Além do seu valor intrínseco, designadamente a chamada de atenção para os determinantes culturais e suas implicações, até no que se refere aos próprios conceitos / construto de inteligência, estes estudos reforçaram a importância dos indícios bem estabelecidos da necessidade de apreciação do pensamento inteligente referenciado a contextos em que exerce e/ou manifesta. Se a metáfora antropológica trata da aculturação em sentido lado, a sociológica trata-a também, embora em sentido mais estrito, colocando o acento na internalização seletiva de interações sociais ou nas aquisições mediadoras, aliás, igualmente seletivas porque orientadas. No processo de socialização, portanto, num determinado nicho cultural. Limitações têm sido apontadas quanto a alguma imprecisão de conceitos envolvidos e a algumas ambigüidades interpretativas. (Por outro lado, em ambos os casos pode questionar-se, pelo menos, se o princípio do relativismo cultural implícito é cientifica e soci- almente neutro nos seus pressupostos como nas suas implicações.)

A metáfora sistêmica incorpora uma noção de inteligência polimórfica e polifacetada, o que subentende diferentes níveis de observação e de análise. A unidade base é o sistema, o conceito nuclear o de interação. Interação de subsistemas, interação com o meio caracterizado pelos contextos do vivido. Modelos ilustrativos, os de Gardner (1999) e Sternberg $(1985,1996)$. Estes modelos são plurimetafóricos, integram diferentes níveis de análise, e incluem aptidões amplas. As dificuldades colocam-se ao nível da complexidade teórica e da operacionalização da teoria.

As metáforas valem o que valem, e a sua utilidade reside no enquadramento que fornecem, no conjunto como isoladamente, aos propósitos do investigador.

\section{Da Auto-Organização e Auto-Governo Mental}

A variedade das teorias da inteligência humana evidenciará complementaridade, no sentido de, em larga medida, decorrer da focalização de determinados aspectos da inteligência, e designadamente relevantes do ponto de vista educacional. A "organização" do funcionamento cognitivo é perspectivada transversalmente, tanto no que se refere aos indivíduos como às situaçōes. Mas a inteligência pode ser entendida como uma qualidade exercida no dia a dia (na escula, no trabalho, nas relações interpessoais, na tomada de decisão), uma auto-organização mental através da qual os acontecimentos, externos como internos, ganham ordenação e significado para o indivíduo. As teorias e as medidas tradicionais cobrem uma parte dessa organização. A articulação dos diferentes aspectos insere-se numa abordagem sistêmica, integradora e compreensiva que, sem pretender substituir-se às formalizações visa, antes, subsumi-las (Sternberg, 1988b).

\section{$O$ modelo triárquico}

A expressão 'teoria triárquica da inteligência humana' (Sternberg, 1985, 1988b) constitui o subtítulo da obra em que é apresentada pela primeira vez, Beyond IQ. Julgo difícil dissociar a escolha do advérbio da postura assumida por L.J. Cronbach, no 
termo de um longo intervalo de 18 anos, relativamente às 'disciplinas' da psicologia científica: de que um rationale teórico compreensivo e extensivo abre caminho à superação de antinomias e à convergência de metodologias. O QI, por seu turno, não constituirá a formulação mais feliz para designar a perspectiva "convencional" ou "tradicional" da avaliação da inteligência, consubstanciada designadamente nas medidas diferenciais; será, no entanto, marcador, enquanto sigla-resumo.

A teoria triárquica articula três sub-teorias expressamente referenciadas ao mundo interno (tratamento da informação), ao mundo externo (interação com o meio), e ao protagonismo da inteligência na adaptação a ambos (as experiências individuais mediadoras). Recupera, agora como sub-teoria, a teoria componencial (Sternberg, 1977) e introduz as subteorias contextual e experiencial.

A sub-teoria componencial trata os mecanismos do comportamento inteligente, mecanismos entendidos como 'componentes', funcionalmente diferenciados numa estrutura hierárquica definida pelo nivel de generalidade: os metacomponentes, os componentes de execução, os componentes de aquisição. Os metacomponentes são processos executivos de ordem superior, que regem o planejamento, a monitorização e a avaliação da atividade cognitiva. Os componentes de execução constituem-se em estratégias reguladoras do funcionamento cognitivo. Os componentes de aquisição organizam o conhecimento (formal, como informal ou tácito) através da filtragem (por codificação, combinaçã̃o e comparação seletivas) da informação nova.

A sub-teoria contextual postula os objetivos comportamentais do pensamento inteligente: a adaptação ao meio; a modelação do meio em função de necessidades e expectativas; a seleção do meio como recurso adaptativo. No centro está, portanto, a adaptação. Ao meio físico e social envolvente à escala macro, como à escala micro - situacional, o meio imediato.

A sub-teoria experiencial facaliza pontos críticos da atividade cognitiva, designadamente a disponibilidade dos mecanismos de processamento da informação e a relativa maleabilidade do repertório comportamental no confronto com o inesperado. A capitalização da experiência anterior na adaptação à novidade traduz-se na eficácia das respostas, em parte resultante de alguma automatização adquirida de processos de resolução de problemas.

As inter-relações das três sub-teorias, do ponto de vista teórico como da operacionalização, cobrem simultaneamente, segundo o autor, os fundamentos e as manifestações do pensamento inteligente. Os componentes atuam em diferentes níveis de atividade e em contextos desigualmente significativos para o indivíduo; e a sua valência adaptativa, bem como a da eficácia dos automatismos de processamento da informação e da facilidade de lidar com situações novas, têm caráter universal. O que não significa que regulações idênticas do pensamento e da ação sejam universalmente adaptativas. O meio tipifica o comportamento inteligente; mas as escolhas possíveis são desigualmente acessíveis e limitadas pela compatibilização das alternativas com as aptidões, as motivações, os valores e os afetos do indivíduo (Sternberg, 1985, 1988b, 1990).

A inteligência integra dinamicamente os mecanismos da cognição, as boas práticas do vivido e a contratualização com o meio, no sentido de autoorganização ao mesmo tempo satisfatória e eficaz. A auto-organização serve o sucesso adaptativo no plano interno, serve o êxito no plano externo. Sucesso e/ou êxito enquanto vivência singular, idiossincrática, segundo os padrões pessoais coincidentes ou não com os estereótipos sociais. Adaptação e ação são indistintamente o verso e o reverso de uma mesma moeda: a elaboração cognitiva, por natureza estruturante, assegura a transformação do dado em adquirido, e as aquisições são estruturas complexas, relativamente estáveis e disponibilizáveis em contexto. A 'moeda' será a inteligência.

A noção de successful intelligence (Sternberg, 1996) ou inteligência funcional (Miranda, 2000) elucida do formato da auto-organização mental. Pensar bem, funcionalmente, implica uma gestão equilibrada dos aspectos analítico, criativo e prático da inteligência, em função dos contextos do mundo real e das metas e dos objetivos que o indivíduo se propõe alcançar. A inteligência analítica direciona os processos mentais para a resolução de problemas e a tomada de decisões. A inteligência criativa gera as idéias e os problemas. A inteligência prática regula a ação no quotidiano. 


\section{Maria José Miranda}

Os grandes aspectos da inteligência constituem as "chaves" do sucesso e do êxito: chave $n^{0} 1$, descoberta de boas soluções, chave $n^{\circ} 2$, descoberta de bons problemas, chave $n^{\circ} 3$, produção e implementação das soluções (Miranda, 2000, prelo, Sternberg, 1996).

A operacionalização, funcional, do modelo triárquico começou a ser ensaiada há quase uma década, visando a construção de uma bateria com níveis diferenciados para desde a infância à idade adulta (Sternberg, 1993). O rationale inclui as sub-estruturas componencial, contextual e experiencial do pensamento aplicado à resolução analítica / criativa I prática de problemas. O material (a amostra de situações e de funções) é apresentado em formato verbal, quantitativo e figurativo.

É ainda dentro do quadro do modelo triárquico que Sternberg se dá conta da sobrevalorização do lado cognitivo da auto-organização mental (Sternberg, 1988b), no sentido da ênfase na transformação da informação em conhecimento explícito ou tácito, transformação mediada pela disponibilidade e progressiva evocabilidade das estratégias operativas. O lado não cognitivo, os processos conativos de controle e orientação das condutas (Reuchlin, 2001), faz parte dessa auto-organiz̧ação, e constitui-se numa modalidade particular do confronto adaptativo, que a designação genérica de "estilos intelectuais" resume. A interface cognitivo / conativo é teoricamente incontornável, detentor de valor heurístico e hermenêutico significativos.

\section{$O$ modelo do auto-governo mental}

No já citado Simpósio dos anos 80 sobre a inteligência e sua medida, R. Sternberg intitula o seu artigo de "A inteligência é auto-governo mental" (Sternberg, 1986). No comportamento inteligente, manifestam-se os processos, as estruturas e as representações mentais reguladoras do pensamento e da ação adaptativos nas várias instâncias das condições habituais de vida. As sociedades humanas dispõem também elas de uma organização que, nos regimes democráticos, regulam as várias instâncias da vida coletiva para o bem comum. A governação das sociedades é o ponto de partida do modelo analógico do auto-governo mental.

O exercício da governação, em termos de com- petências e áreas de influência, pode ser categorizado em Funções, Níveis, Tendências, Formas, e Âmbitos. Legislar / executar / avaliar, correspondem às Funções legislativa, executiva e judicial. A administração central / regional, aos Níveis global e local. Os grandes princípios orientadores, às Tendências liberal e conservadora. As estratégias de ação, às Formas hierárquica / monárquica / oligárquica / anárquica. A soberania nacional e a concertação internacional, aos Âmbitos interno e externo.

Os indivíduos e as sociedades são sistemas auto-organizados. A competência adaptativa reflete a qualidade da auto-organização, das aptidões como dos motivos, interesses e afetos. As aptidões refletem-se no Nivel adaptativo. Os motivos, interesses e afetos, no ESTILO adaptativo. Auto-organização mental inclui, por definição, auto-governação.

No plano individual como no plano social, a função legislativa liga-se à criação / formulação / planejamento de objetivos; a função executiva à sua implementação; a função judicial à monitoragem e avaliação desta; o nível global tem a ver com grau elevado de abstração e com o processamento de um todo em conjunto; o nível local com o pormenor de concepção e realização; a tendência liberal maximiza a flexibilidade de regras e procedimentos, a conservadora privilegia normas e práticas estipuladas. Também no plano individual, como no social, e no que respeita as estratégias de ação, a forma hierárquica pondera e ordena objetivos, a forma monárquica focaliza-os isoladamente, a forma oligárquica considera-os no conjunto, a forma anárquica aleatorizaos; no que respeita os teatros de ação, o âmbito interno supõe delimitação, o externo interação. No plano social, como no plano psicológico, as funções são exercidas em contextos mais ou menos largos (níveis), com maior ou menor flexibilidade (tendências), com uma estruturação variável (formas), e em situações mais ou menos amplas (âmbitos); embora qualquer função seja teoricamente compatível com qualquer nível, tendência, forma ou âmbito de atuação, alguns agrupamentos são mais freqüentes e, eventualmente, mais eficazes.

As variedades das cinco dimensões constituem os 13 estilos de pensamento: Legislativo, Executivo e Judicial; Global e Local; Liberal e Conservador; Hierárquico, Monárquico, Oligárquico e Anár- 
quico; Interno e Externo. No modelo da inteligência como auto-governo mental, a idiossincrasia é descrita em termos dos estilos: os indivíduos evidenciam preferências no confronto com o real, e recorrem em contexto a combinações estilísticas. Os estilos interagem com as aptidões, e são interdependentes. Diferenças individuais ocorrem quanto ao estilo dominante, e quanto às combinações. A socialização maximiza a flexibilidade das relações do indivíduo consigo mesmo, com os outros e com as coisas. (Miranda, 1994, 1999; Sternberg, 1986, 1988a, 1988b).

O Inventário de Estilos de Pensamento - IEP (Miranda, 1994, 1996-2000, 1999; Sternberg \& Wagner, 1991) operacionaliza o modelo. Trata-se de um inventário de auto-descrição, para adolescentes e adultos. É constituído por 13 escalas, os 13 estilos de pensamento, de 8 itens cada. A resposta é numa escala tipo Likert de sete pontos: o indivíduo situa-se relativamente a cada afirmação em termos de como ela se aplica a si. O resultado bruto de cada escala é o quociente do somatório dos pontos pelo número de itens. O resultado derivado, um percentil. O protocolo individual traduz um perfil estilístico geral.

$A$ adaptação portuguesa do IEP foi aplicada a amostras portuguesas do terceiro ciclo do Ensino Básico ( $7^{\circ}-9^{\circ}$ anos de escolaridade), do Ensino Secundário ( $10^{\circ}-12^{\circ}$ anos de escolaridade), de universitários, e de adultos em geral. A análise dos resultados, por amostra, incluiu estudos diferenciais, metrológicos e normativos.

O primeiro aspecto sobressalente é o da interculturalidade do modelo: a comparação de resultados das amostras americanas e portuguesas pôs em evidência semelhanças esperadas. Um segundo aspecto, a sua natureza desenvolvimentista: efetivamente, e em ambas as amostras culturais, as distribuições de resultados dos grupos definidos por variáveis independentes invocadas são distintas, não obstante configuração gaussiana da distribuição dos resultados de cada escala.

Um terceiro aspecto a salientar, transversal nas quatro amostras, respeita a operacionalização: por um lado, a precisão dos resultados das escalas é elevada e significativa em níveis exigentes de probabilidade; por outro, a evidência relativa à estrutura interna do instrumento (matrizes de intercorrelações e matrizes fatoriais) é consistente com o modelo teórico.

\section{Considerações Finais}

A problemática da inteligência humana cruza toda a história do pensamento ocidental. A questão da inteligibilidade é primacial na história das idéias, como terá sido primacial na sobrevivência da espécie.

A psicologia científica autonomizou-se pelo seu objeto - a consciência, e pela sua metodologia de análise experimental - o impacto nela provocado pela manipulação de estímulos do meio. Por analogia com as leis das ciências físicas, as leis do comportamento do organismo humano, convenientemente equipado para interagir significativamente com o meio, seriam universais. A mesma analogia ditava a orientação no sentido do elementarismo, da redução dos fenômenos observáveis às unidades de análise tão simples quanto possível.

A perspectiva molecular cedo se revelou inoperante para dar conta das modalidades de interação indivíduo / meio. O indivíduo é um sujeito, um sujeito ativo e responsivo. E um sujeito de pensamentos e de afetos.

Os princípios e os métodos da psicologia geral por um lado, e da psicologia diferencial por outro, enquadraram os desenvolvimentos teóricos e práticos da pesquisa ao longo de mais de um século. Determinaram opções mais frequientemente estanques do que confluentes.

Ao longo de todo esse período, a evolução das técnicas estatísticas de tratamento de dados foram determinantes: a análise fatorial como primeiro ensaio de modelização estrutural, a análise de variância como primeiro ensaio de modelização de interações, e posteriores desenvolvimentos e aproximações, abriram caminho aos modelos multivariados e aos modelos integrados. A psicometria (Dickès, 2001) ligou definitivamente a psicologia geral e a psicologia diferencial.

Não menos determinantes foram os caminhos abertos pelos estudos de sujeito único, de formato clínico como laboratorial. Do ponto de vista epistemológico, do ponto de vista metodológico, do ponto de vista da articulação da evidência obtida em domínios diferenciados.

As perspectivas interdisciplinar e plurimetodológica afiguram-se constituir o contorno de 
todos os possíveis da pesquisa psicológica. No centro está o sujeito, o sujeito gnoseológico e axiológico, a pessoa: 0 eu que conhece e sente, que se reconhece o protagonista desse conhecer e desse sentir (Damásio, 1999), se constrói pela alteridade, que cria, inventa e transmite, e que interioriza valores. Na história da psicologia da inteligência humana, a adaptação foi ganhando sentido psicológico e lugar central na pesquisa, mesmo quando não diretamente referida.

$\mathrm{Na}$ natureza, toda a adaptação é compatibilidade vital. A racionalidade, porém, impõe ao ser humano a inteligibilidade, condição dessa forma superior de adaptação, a coincidência vivida.

Cabe à ciência esclarecer como cada um é como todos os outros, mais como alguns outros, mas como nenhum outro. E descrever os mecanismos da apropriação, que inclui postular as condições favoráveis da sua disponibilização e transferência. $E$ fornecer as ferramentas da auto-ajuda e da entre-ajuda, e das suas consequiências últimas, o diálogo com a natureza e com a cultura.

\section{Referências Bibliográficas}

Brody, N. (2000). History of theories and measurements of intelligence. In R.J. Sternberg (Ed.) Handbook of Intelligence (16-33). Cambridge: Cambridge University Press.

Cattell, R.B. (1987). Intelligence: its structure, growth and action. Amsterdam: North-Holland.

Damásio, A.R. (1994). Descartes' error. Emotion, reason and human brain. New York: Oxford University Press.

Damásio, A.R. (1999). The feeling of what happens. Body and emotion in the making of consciousness. New York: Harper.

Dickès, P. (2001). La psychométrie comme lien entre psychologie différentielle et psychologie générale. In A. Flieller et al. (Eds.) Questions de psychologie différentielle (pp. 45-53). Rennes: Presses Universitaires de Rennes.

Eysenck, H.J. (Ed.) (1982). A Model for Intelligence. New York: Springer.

Gardner, H. (1999). Intelligence Reframed. Multiple Intelligences for the $21^{\text {st }}$ Century. New York: Basic Books.
Hebb, D.O. (1949). The organization of behavior. A neuropsychological theory. New York: Wiley.

Kuhn, T.S. (1983). La structure des révolutions scientifiques. Paris: Flammarion.

Mattarazzo, J.D. (1992). Psychological testing and assessment in the XXIst century. American Psychologist, 47 (8), 1007-1018.

Miranda, M.J. (1986). Perspectivas da investigação e avaliação da inteligência. Revista Portuguesa de Psicologia, 23, 27-54.

Miranda, M.J. (1994). Estudo do Inventário de Estilos de Pensamento com estudantes universitários: dados metrológicos, Psychologica,12, 131141.

Miranda, M. J. (1996-2000). Manual do Inventário de Estilos de Pensamento. I - Estudantes universitários, II - Ensino Básico, III - Ensino Secundário. Lisboa: Centro de Psicometria e Psicologia da Educação.

Mranda, M.J. (1999). L'intelligence comme autogouvernement mental: du modèle à la mesure des styles cognitifs. In M. Huteau \& J. Lautrey (Eds.) Psychologie et Différences Individuelles (pp. 197-200). Rennes: Presses Universitaires de Rennes.

Miranda, M.J. (2000). La investigación psicológica de la inteligencia humana: balance del siglo en la transición del milenio. Persona, Revista de la Facultad de Psicología de la Universidad de Lima, 3, 27-45.

Miranda, M.J. (no prelo). A psicologia da inteligência humana em perspectiva: de onde vimos e para onde vamos? Arquipélago, Revista da Universidade dos Açores.

Neisser, U. (1979). The concept of intelligence. In R.J. Sternberg \& D.K. Detterman (Eds.) Human Intelligence. Perspectives on its theory and Measurement (179-189). Norwood: Ablex.

Reuchlin, M. (1999). Evolution de la psychologie différentielle. Paris: PUF.

Reuchlin, M. (2001). La psychologie différentielle (8e. éd.). Paris: PUF.

Sternberg, R.J. (1977). Intelligence, Information Processing and Analogical Reasoning: The componential analysis of Human Abilities. New York: Wiley.

Stemberg, R.J. (1979). A review of 'Six authors in 
search of a character'. A play about intelligence tests in the year 2000. In R. J. Sternberg \& D. $\mathrm{K}$. Detterman (Eds.) Human Intelligence. Perspectives on its Theory and Measurement. (257-267). Norwood: Ablex.

Sternberg, R.J. (1985). Beyond IQ. A Triarchic Theory of Human Intelligence. Cambridge: Cambridge University Press.

Sternberg, R. J. (1986). Intelligence is mental selfgovernment. In R. J. Sternberg \& D. K. Detterman (Eds.) What is intelligence? Contemporary viewpoints on its nature and definition (141-148), Norwood: Ablex.

Sternberg, R.J. (1988a). Mental self-government: a theory of intellectual styles and their development, Human Development, 31, 197-224.

Sternberg, R.J. (1988b). The Triarchic Mind. A New Theory of Human Intelligence. New York: Viking.

Sternberg, R.J. (1993). Sternberg Triarchic Abilities Test. (Unpublished test).

Sternberg, R.J. (1990). Metaphors of the Mind. Conceptions of the Nature of Intelligence. Cambridge: Cambridge University Press.

Sternberg, R.J. (1996). Successful Intelligence. New York: Simon \& Schuster.

Sternberg, R.J. (2000). The concept of intelligence. In R. J. Sternberg (Ed.) (2000). Handbook of Intelligence. Cambridge: Cambridge University Press, 3-15.

Sternberg, R.J., Conway, B.A., Ketron, J.L. \& Bernstein, M. (1981). People's conceptions of intelligence, Journal of Personality and Social Psychology, 41, 37-55.

Sternberg, R.J. \& Detterman, D. K. (Eds.) (1986). What is intelligence? Contemporary viewpoints on its nature and definition. Norwood: Ablex.

Sternberg, R.J. \& Wagner, R. (1991). MSG Thinking Styles Inventory - Manual. New Haven: Yale University.

Thorndike, E.L. et al. (Eds.) (1921). Intelligence and its measurement: a symposium. Journal of Educational Psychology, 12, 123-147, 195-216.

Vernon, $\mathrm{Ph}$. A. et al. (2000). The neuropsychology and psychophysiology of human intelligence. In R.J. Sternberg (Ed.) (2000). Handbook of Intelligence. (245-264) Cambridge: Cambridge
University Press.

Wechsler, D. (1975). Intelligence defined and undefined. American Psychologist, 30, 135-139. 
